University of Nebraska - Lincoln

DigitalCommons@University of Nebraska - Lincoln

Faculty Publications, Department of Psychology

Psychology, Department of

September 1993

\title{
Sexual Practices and Attitudes of Street Youth in Belo Horizonte, Brazil
}

Marcela Raffaelli

University of Nebraska-Lincoln, mraffaelli1@unl.edu

Regina Campos

Universidade Federal de Minas Gerais, Belo Horizonte, MG, Brazil

Alice Payne Merritt

Johns Hopkins School of Hygiene and Public Health

Eliana Siqueira

Universidade Federal de Minas Gerais, Belo Horizonte, MG, Brazil

Carlos Mauricio Antunes

Universidade Federal de Minas Gerais, Belo Horizonte, MG, Brazil

See next page for additional authors

Follow this and additional works at: https://digitalcommons.unl.edu/psychfacpub

Part of the Psychiatry and Psychology Commons

Raffaelli, Marcela; Campos, Regina; Merritt, Alice Payne; Siqueira, Eliana; Antunes, Carlos Mauricio; Parker, Richard; Greco, Marilia; Greco, Dirceu; Halsey, Neal; Bolt, Elizabeth; Jeronymo, Mauro Lucio; Kendall, Carl; Ottoni, Zelia; Pinto, Jorge Andrade; Rolf, Jon; Ruff, Andrea; Ude, Walter; and de Zalduondo, Barbara, "Sexual Practices and Attitudes of Street Youth in Belo Horizonte, Brazil" (1993). Faculty Publications, Department of Psychology. 148.

https://digitalcommons.unl.edu/psychfacpub/148

This Article is brought to you for free and open access by the Psychology, Department of at DigitalCommons@University of Nebraska - Lincoln. It has been accepted for inclusion in Faculty Publications, Department of Psychology by an authorized administrator of DigitalCommons@University of Nebraska - Lincoln. 


\section{Authors}

Marcela Raffaelli, Regina Campos, Alice Payne Merritt, Eliana Siqueira, Carlos Mauricio Antunes, Richard Parker, Marilia Greco, Dirceu Greco, Neal Halsey, Elizabeth Bolt, Mauro Lucio Jeronymo, Carl Kendall, Zelia Ottoni, Jorge Andrade Pinto, Jon Rolf, Andrea Ruff, Walter Ude, and Barbara de Zalduondo 


\title{
Sexual Practices and Attitudes of Street Youth in Belo Horizonte, Brazil
}

\author{
Marcela Raffaelli, Department of Psychology, Rutgers University \\ Regina Campos, Universidade Federal de Minas Gerais, Belo Horizonte, MG, Brazil \\ Alice Payne Merritt, Johns Hopkins School of Hygiene and Public Health \\ Eliana Siqueira, Universidade Federal de Minas Gerais, Belo Horizonte, MG, Brazil \\ Carlos Mauricio Antunes, Universidade Federal de Minas Gerais, Belo Horizonte, MG, Brazil \\ Richard Parker, Universidade do Estado do Rio de Janeiro, Rio de Janeiro, RJ, Brazil \\ Marilia Greco, Universidade Federal de Minas Gerais, Belo Horizonte, MG, Brazil \\ Dirceu Greco, Universidade Federal de Minas Gerais, Belo Horizonte, MG, Brazil \\ Neal Halsey, Johns Hopkins School of Hygiene and Public Health \\ The Street Youth Study Group — Elizabeth Bolt, Mauro Lucio Jeronymo, Carl Kendall, Zelia Ottoni, \\ Jorge Andrade Pinto, Jon Rolf, Andrea Ruff, Walter Ude, and Barbara de Zalduondo
}

\begin{abstract}
Street youth are at risk of HIV infection worldwide. To develop effective prevention strategies, information about the meanings and functions of sexual activity for street youth is needed. In this paper, data from structured questionnaires, focus group discussions, in-depth interviews and field observations are used to build up a picture of the sexual culture of 9-to-18-year-olds living and/or working on the streets of a large Brazilian city. The findings reveal that these children and adolescents engage in sexual behavior that puts them at risk of sexually transmitted diseases, including HIV/AIDS, and reinforce that sex is a multi-determined and entrenched behavior in this population. Interventions must take into account the fact that for street youth, sex is used as a means of ensuring survival, seeking comfort, finding pleasure, and dealing with psychological issues that arise during adolescence.
\end{abstract}

Key words: street youth, Brazil, AIDS

Millions of children and adolescents live and/or work on the streets of large cities worldwide [1]. These youngsters have usually left school and sometimes left home; they survive by scavenging, begging, stealing, exchanging sex for money, or working in the 'informal sector' at low-paying and frequently dangerous jobs [2]. Street youth are known to engage in sexual activity with peers and adults from within and outside their social circle. Sex satisfies multiple needs for street children and adolescents [3]. To earn money or obtain food, clothes or shelter, they may engage in "survival sex" with adults $[4,5]$. Within the peer group, sex is used for entertainment and comfort as well as to exert power and establish dominance [6]. The outlines of street youth sexual behavior are well defined, but little has been done to fill in the picture. This is partly because child and adolescent sexuality are taboo topics in most cultures $[7,8]$, partly because a discussion of street youth sexuality must expose members of the dominant culture [5], and partly because emphasis has been laid on service programs rather than research [9].

The study of street youth sexuality has become increasingly relevant because this population is at risk for acquired immunodeficiency syndrome (AIDS) [3, 10-13]. Because of the long latency period (averaging 7-10 years) between infection with the human immunodeficiency virus (HIV) and the onset of AIDS, few of the world's reported AIDS cases have occurred in adolescents. However, epidemiological studies conducted in different countries show elevated HIV seropositivity rates among street youth compared to the general adolescent population $[10,11]$. A fair amount of research on sexual behavior and risk for HIV among homeless youth has been carried out in North America [14-16], but little research has been conducted elsewhere $[13,17]$. This has hindered prevention efforts, because information on patterns of sexual behavior is needed to guide the design of appropriate and relevant intervention programs. To change HIV risk behavior, we must first understand a group's sexual culture, "the systems of meaning, of knowledge, beliefs, and practices, that structure sexuality in different social contexts" [18, p. 79]. As a first step, we examine sexual practices and attitudes of a sample of Brazilian street youth.

Brazil is a country where both AIDS and street youth are becoming increasingly problematic. Brazil, with 150 million inhabitants, is now fourth in the number of AIDS cases worldwide, with 31,466 cases reported as of October 1992 [19]. The spread of HIV has occurred rapidly in Brazil, in part because of the way sexual culture is constructed [20]. For example, individuals are classified by whether they act as the active or passive partner during sexual activity; thus, a "man" can have sex with both males and females without losing his male (heterosexual) identity as long as he takes the "active" (insertive) role [21]. This cultural construction of sexuality has had an impact on the HIV/AIDS epidemic. Although initial AIDS cases occurred among "homosexual" men, HIV spread rapidly through- 
out society. The primary risk factors for notified AIDS cases have shifted between 1980-86 and 1992 from "homosexual" and "bisexual" activities (dropping from $47 \%$ to $23 \%$, and $22 \%$ to $11.5 \%$, respectively) to heterosexual activity and intravenous drug use (rising from $5 \%$ to $22 \%$, and $3 \%$ to $25 \%$, respectively) [19]. Another factor that has influenced the progression of the AIDS epidemic is a cultural emphasis on sexual practices that have been identified as facilitating HIV transmission, particularly unprotected anal [20] and vaginal [22] intercourse. It is within this larger sexual culture that street youth sexuality is structured and played out.

Estimates of the number of Brazilian youth who work on the streets range from 7 to 17 million, and estimates of the number of youth who live on the streets range up to 7 million [2]. In the country as a whole, only $3.2 \%$ of reported AIDS cases have occurred in 10-19 year olds, but $32.9 \%$ have occurred among 20-29 year olds [19], many of whom probably became infected during adolescence. Street children are at increased risk of HIV infection because their lack of formal education, fugitive status, and inaccessibility makes them a difficult population to reach and work with, and lack of information about their sexual behavior impedes the development and implementation of educational interventions.

Youth surviving on the street in Brazilian cities are known to engage in sexual activity, although details are sketchy. According to a magazine article, "in the street, the kids play like children, love like adults, and steal like bandits" [23]. Street youth workers in Brazil have described the precocious sexualization children face on the street [24-26]; however, few systematic examinations of sexual practices have been conducted. One ethnographic study revealed that street boys and girls in Rio de Janeiro engage in high-risk sexual activity, including unprotected anal and vaginal intercourse [27], and pointed to the related risk of HIV infection. An epidemiological study conducted with 82 street youth in Sao Paulo revealed that $6 \%$ were HIV positive [28]; government estimates of HIV seroprevalence rates range from $1.5 \%$ among a sample of delinquent and impoverished youth in Rio de Janeiro to $7.5 \%$ among street youth in a Sao Paulo detention center [29]. Epidemiological research conducted as part of the present study revealed that of 39410 18 year olds assessed during medical examinations in Belo Horizonte, four (1.0\%) tested HIV-positive [30].

These studies show that street youth are at risk of HIV infection, but in the absence of more detailed information about the circumstances, functions, and meanings of sexual activity, little can be done to reduce that risk. This paper presents information about sexuality and high-risk behavior among Brazilian street youth, focusing on the following themes: sexual partners and practices, motivations for sexual activity, contraception, pregnancy, sexually transmitted diseases, drug use linked to high risk behavior, and attitudes towards sexuality.

\section{METHODS}

\section{Description of the study}

The data presented here were gathered as part of the project "HIV in street youth: epidemiology and prevention," carried out by a multidisciplinary team from the Federal University of Minas Gerais, Belo Horizonte, Brazil, and the Johns Hopkins School of Hygiene and Public Health, Baltimore, U.S.A. This project studied HIV seroprevalence and risk factors, and conducted interventions to reduce the risk of HIV infection, among children and adolescents living and/or working on the streets of Belo Horizonte, the fourth largest city in Brazil.

\section{Sample}

The study utilized multiple methods of data collection; samples studied with each method are summarized in Table 1 and described more fully below. The target population for the study was 9-18-year-olds who spend time on the street, working in the "informal economy" (e.g. selling food or flowers, washing cars, collecting paper) or engaging in illicit activities (e.g. stealing, drug dealing, exchanging sex for money). Youngsters were studied in different locations, including state and religious institutions, neighborhoods of origin, and the streets.

\section{Measures and procedures}

Informed consent. This research was authorized by the state juvenile court (juizado dos menores) which has jurisdiction over street youth, and was approved by institutional review boards at both collaborating institutions. Verbal consent was obtained from all study participants.

\section{Qualitative measures.}

(1) Focus group discussions (FGD) were conducted by three researchers (one male, two female) with 53 youth (27 male, 26 female) recruited through six state and religious institutions. These focus groups .provided information about sexual norms, practices, attitudes, and language, and about HIV/AIDS-related knowledge, attitudes, and practices. Discussions were tape-recorded and transcribed.

(2) Open-ended interviews were conducted by a female researcher with 15 youth (10 male, 5 female) in street settings and shelter houses. Topics included life situation, origins, sexual behavior, drug use, health, and AIDS knowledge and attitudes of street youth in general. Responses were hand-written and expanded after the interview.

(3) Life history interviews were conducted by the same researcher with two young women, and by a male researcher with four male street youth. Youth were previously known to the researchers and were selected because they represented typical street youth. These interviews were tape-recorded and transcribed. 
Table 1. Number and ages of youth studied with each assessment procedure

\begin{tabular}{lccccc}
\hline & \multicolumn{2}{c}{ Boys } & & \multicolumn{2}{c}{ Girls } \\
\cline { 2 - 3 } \cline { 5 - 6 } \cline { 5 - 6 } & Number & Age range & & Number & Age range \\
\hline Focus groups & 27 & $10-18$ & & 26 & $13-18$ \\
Open-ended interviews & 10 & $12-18$ & & 5 & $12-18$ \\
Life history interviews & 4 & $14-20$ & & 2 & $17-22$ \\
Pilot structured interviews & 48 & $10-17$ & & 17 & $11-17$ \\
Structured street surveys & 291 & $9-18$ & & 88 & $9-18$ \\
\hline
\end{tabular}

(4) Field observations were carried out sporadically over a 15-month period by the same two researchers in youth's natural settings, including the city streets and squares where they spend their days, the highway overpasses and abandoned houses where they seek shelter at night or in inclement weather, and the open houses where they go for food and access to shower and laundry facilities. Ninety-three days of field notes were handwritten in notebooks and transcribed.

\section{Quantitative measures.}

(1) Pilot structured interviews were conducted by a female social worker at the state child welfare agency with 65 youth (48 male, 17 female). The interview instrument served as the basis for the structured questionnaire used in a large-scale street survey (below). Questions on knowledge about pregnancy and contraception were included only in the pilot instrument and are described in this paper.

(2) Structured questionnaires were administered to youth recruited and interviewed on the streets during a 10day period by 21 interviewers (11 male, 10 female). The street survey included questions on family background, daily life, institutional experiences, travel, drug use, sexual practices, and AIDS knowledge and attitudes. Interviewers were college students and youth workers who attended a one-week training course. Interviewers worked in pairs at designated locations and spot-checks were carried out by two roving supervisors. Interviewers approached all youth in their assigned locations, explained the study and invited them to participate. At the end of the interview youth received a meal ticket redeemable at local restaurants.

Because identifying information was obtained only after youngsters had agreed to be interviewed, and was optional, the exact participation rate is unknown. Tallies kept by interviewers indicate that $62 \%$ of the youngsters they approached completed the interview. A total of 413 interviews were administered. Examination of identifying information (e.g. name, nickname, date of birth, interviewers' descriptive notes) revealed that 32 respondents repeated the interview more than once. Two others were over the cut-off age of 18. Repeated and over-age interviews were excluded, leaving 379 respondents. The final sample consisted of 291 boys (mean age 13.9 years) and 88 girls (mean age 14.6 years).

Participants were categorized by age group $(9-12,13-$ 15 , or 16-18) and by whether they were "home-based" (46.8\%) or "street-based" (53.2\%). Home-based youth were all those who "always or almost always" slept at home $(N=$ 156 ), and those who slept in other non-street locations but had frequent family contact (daily or weekly) and did not engage in illegal survival activities $(N=20)$. Street-based youth were all those who slept on the street alone or with peers $(N=152)$, and those who reported sleeping in other non-street locations but had rare family contact (monthly or never) and/or engaged in illegal survival activities $(N$ $=48$ ). This classification corresponds to the distinction between youth "on" and "of" the streets made by researchers and advocates $[2,9]$.

Data processing and analyses. The qualitative data transcripts were analyzed by topic to reveal group patterns of experience. Triangulation of the different data sets (FGD, open-ended interviews, life history interviews, and field observations) was carried out to check for consistency of information across methods. Examples cited in this paper were selected for their representativeness in the data set and for illustrative purposes.

Data from the structured street survey interviews were entered using the SPSS data entry program for microcomputer. Accuracy of the data was ensured by defining range limits and valid values for all variables, and double data entry was carried out with a subset of the interviews to check for data entry errors. Analyses were carried out using SPSS-PC for microcomputer .

Data from the different assessments were analyzed thematically to build up a picture of the sexual culture of street youth. The street survey was used to quantify behavior and the qualitative material to provide information about attitudes and motives, and to illustrate the survey findings.

\section{RESULTS}

As a first step, survey respondents were asked about their same-sex friends' sexual behavior, and responses revealed that street youth live in a risky sexual environment. Equal proportions of boys and girls reported that their friends were sexually active (71.5\%), exchanged sex for money $(32.3 \%)$, had sex under the influence of alcohol or drugs $(42.9 \%)$, and had sexually transmitted diseases $(39.4 \%)$. Sixty-nine percent of the girls said their friends had been pregnant, and $43.4 \%$ that their friends had abortions. Forty-four percent of the boys said their friends had impregnated a girl or woman. 
The majority of street survey respondents said that they themselves had initiated sexual activity (66.3\% of boys, and $61.4 \%$ of girls). The proportion of youth reporting being sexually active increased steadily with age, with a non-significant trend for more boys than girls to report being sexually active until the age of 15 (Fig. 1). More street-based than home-based youth reported being sexually active at all ages (Table 2). Because life circumstance variables reflected current experience, it was not possible to determine what predicted sexual initiation. The remainder of this paper focuses on the sub-sample of youth who reported having sexual experience.

\section{Sexual initiation}

Youngsters reported that sexual initiation occurred at an early age, and was frequently the result of coercion, particularly for girls. The mean age of first sexual experience reported by street survey respondents was 11.2 years, with boys reporting earlier initiation than girls (Table 3). Most boys reported that their first partner was a peer, but over two fifths of the girls had their first sexual experience with an adult man (Table 3).

Further analyses revealed that age at first sexual experience was matched to partner's age for boys but not girls. Boys whose first experience occurred at or before age 12 were more likely to report that their partner was a female peer $(86.3 \%$ vs $50 \%$ of boys who initiated sex after age 12$)$, whereas those whose first experience occurred after age 12 were more likely to report that their partner was an adult woman $(40 \%$ vs $8.4 \%)\left(\chi^{2}=28.7, d f=3, P=0.00001\right.$.) In
Table 2. Proportion of street-based and home-based youth reporting sexual experience by age group

\begin{tabular}{|c|c|c|c|}
\hline Age group & Home-based & Street-based & Total \\
\hline $9-12$ year olds & 32.4 & $60.7 *$ & 39.8 \\
\hline 13-15 year olds & 50.0 & $82.6^{* *}$ & 67.0 \\
\hline $16-18$ year olds & 72.2 & $92.5 *$ & 88.0 \\
\hline
\end{tabular}

Data source: street survey. Differences between home-based $(N=$ $176)$ and street-based $(N=200)$ youth; significance levels: ${ }^{*} P<$ $0.05 ; * * P<0.0001$.

contrast, girls whose first sexual experience occurred before or after age 12 were equally likely to report that their first partner was a male peer (50\% vs $53.3 \%)$ or an adult man $(36.4 \%$ vs $46.7 \%)$. The qualitative materials highlight that many girls are forced into initiating sexual activity:

The boys used to say these things to me, I would cry from fear. Then one day, I was so afraid, one day I tried it, you know? But the pain was so bad, I went and threw the boy off and ran away. I threw him far, like this: Pah! And he said 'What's this, girl, are you trying to make me crazy?' My body was all limp, I was very nervous, all red from the pain there, then, I don't know what happened to me, because I was very high. I think they gave me something to drink, you know? So they went and they managed ... . They managed ... A Ah! But when I got up, I hadn't seen anything, I didn't know who it was. (K., female, 17)

- There are married men, they see a young girl. When they see a girl like that, they start to give her money. They give money to buy a soda, tell her they're going to buy clothes.

- They give presents.

- They lie to the girl, then they stick it to her.

(Boys, FGD)

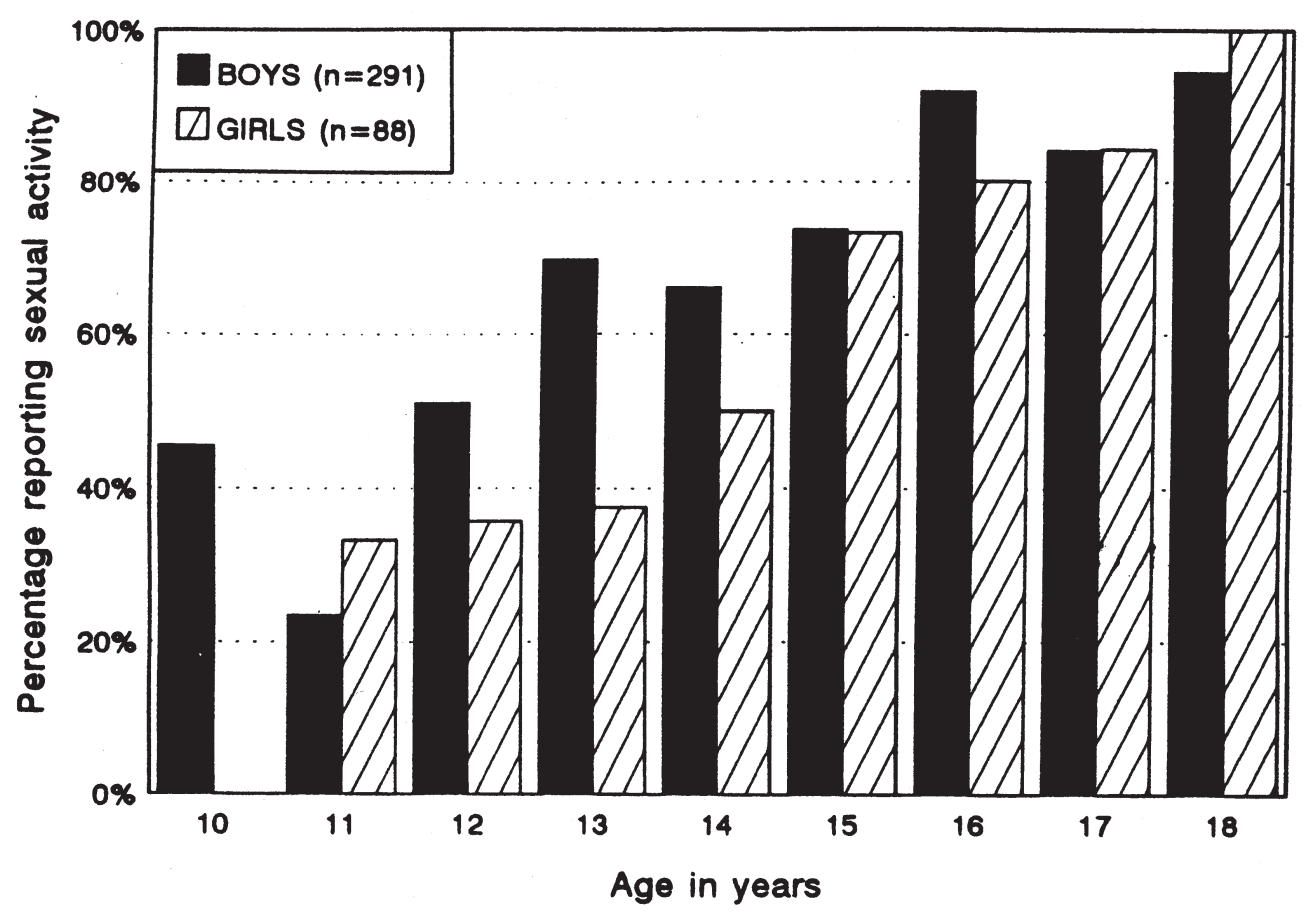

Fig. 1. Percentage of youth reporting sexual activity by age (data source: street survey). 


\section{Sexual partners and practices}

Youth reported having sexual relations with a variety of partners from within and outside their social group for a variety of reasons. In the focus groups and in-depth interviews, sex with peers was most frequently described as being for pleasure, protection, or behavioral control, whereas sex with adults occurred in exchange for money, material objects, or leisure resources. In the street survey, lifetime sexual experience was assessed. Because preliminary analyses revealed systematic differences attributable to gender and age, but fewer differences attributable to being home or street-based, results are presented by gender and age in tables. Significant differences that emerged between homebased and street-based boys and girls (controlling for age) are presented in the text.

Boys'sexual partners and practices. Most boys reported sex with opposite-sex partners, and although vaginal intercourse was most common, many boys had also experienced anal or oral intercourse with female partners (Table 4).

More street- than home-based boys reported sex with an adult woman when age was controlled $\left(64 \%\right.$ vs $21 \% ; \chi^{2}$ $=16.9, d f=3, P=0.0002)$. The qualitative materials suggest that the main motivation for sex with female partners is pleasure; boys described these sexual encounters as one of their greatest sources of enjoyment. In addition, some youth described being paid by older women to have sex with them, a finding that was confirmed by the street survey, where $13.5 \%$ of sexually active boys reported earning money by having sex with women.

Same-sex encounters were reported by a third of all sexually active boys; the majority of these boys had experienced anal intercourse with their male partners, and a lesser proportion oral intercourse (Table 4). Sex with adult men was typically described as taking place in exchange for something: money, food, clothing, and other material goods. A third of the boys interviewed during the street survey said their male friends exchanged sex for money, and 7\% admitted that they themselves had done so. The qualitative materials hint that this practice is common, as it was openly described by youth:

Table 3. Age and partner of sexual initiation

\begin{tabular}{|c|c|c|c|}
\hline & $\begin{array}{c}\text { Boys } \\
(N=193)\end{array}$ & $\begin{array}{c}\text { Girls } \\
(N=54)\end{array}$ & $\begin{array}{c}\text { Total } \\
(N=247)\end{array}$ \\
\hline Mean age initiation (yr) & 10.8 & 12.4 & \\
\hline $11.12 *$ & & & \\
\hline Percentage initiated by age 12 & 72.7 & 41.5 & $65.7 *$ \\
\hline \multicolumn{4}{|c|}{ Percentage whose first partner was: } \\
\hline Opposite-sex peer & 75.9 & 51.9 & $70.8^{*}$ \\
\hline Same-sex peer & 4.7 & 1.9 & 4.1 \\
\hline Opposite-sex adult & 17.3 & 42.3 & $22.6^{*}$ \\
\hline Same-sex adult & 2.1 & 3.8 & 2.5 \\
\hline
\end{tabular}

Data source: street survey; youth with sexual experience only.

Differences between boys and girls: $* P<0.001$. Anovas examining gender differences in mean age of first sexual experience controlled for current age.
Table 4. Partners and practices or sexually active street youth

\begin{tabular}{lcc} 
& $\begin{array}{c}\text { Boys } \\
(N=193)\end{array}$ & $\begin{array}{c}\text { Girls } \\
(N=54)\end{array}$ \\
\cline { 2 - 3 } & & \\
Opposite-sex partner(s) & 97.4 & 98.1 \\
Peer & 95.8 & $66.0^{* * *}$ \\
$\quad$ Vaginal & $(96.2)$ & $(100.0)$ \\
$\quad$ Anal & $(42.4)$ & $(17.1)^{* *}$ \\
Oral & $(28.3)$ & $(31.4)$ \\
Adult & 50.0 & 61.1 \\
$\quad$ Vaginal & $(97.9)$ & $(97.0)$ \\
$\quad$ Anal & $(47.4)$ & $(21.2)^{* *}$ \\
Oral & $(34.7)$ & $(30.3)$ \\
Same-sex partner(s) & 33.5 & 11.1 \\
Peer & 25.3 & $5.6^{* *}$ \\
$\quad$ Anal & $(89.6)$ & - \\
Oral & $(27.1)$ & $(100.0)^{* *}$ \\
Adult & 16.9 & $5.6^{*}$ \\
$\quad$ Anal & $(81.2)$ & - \\
$\quad$ Oral & $(47.3)$ & $(100.0)$ \\
Any partner(s) & & \\
Vaginal intercourse & & \\
Anal intercourse & 95.3 & 96.3 \\
Oral intercourse & 62.7 & $20.4^{* * * *}$ \\
Risk behaviors & 38.3 & 35.2 \\
Exchange sex for money & & \\
Sex while using alcohol/drugs & 16.1 & 20.4 \\
Previous STD & 43.0 & 49.0 \\
Ever used condoms & 21.2 & 15.3 \\
Used condoms at last intercourse & 15.6 & $27.8^{*}$ \\
Da & 8.8 & 13.0 \\
& &
\end{tabular}

Data source: street survey; youth with sexual experience only.

Data show percentage or respondents reporting each type or experience. Figures in parentheses reflect percentages for youth reporting different types of sexual experience with each type or partner .

Differences between boys and girls: $* P<0.10$; $* * P<0.05$; $* * P<$ 0.001 .

- They have cars.

- Sometimes they take us to their apartment, other times just to a vacant lot.

- [Are they younger or older?]

- Older.

- Some of them are even married.

(Boys, FGD)

I was sitting in the square one Saturday. This transvestite came along. He was in the car, he called me to go out with him. I thought it was a woman. Afterwards. ..the voice was strange. Then I discovered it was a fag. Then, we were already far, I said 'I'll go, what the heck.' So I went with him. He gave me money and I went away. (B., male, 19 years)

Although most same-sex encounters with adults involved money, other forms of exchange were described:

-We do it with them without money too. The desire is too much ... you don't need money.

- Sometimes we do it with money or without money, when we need money [later] and go up to them and ask, then they give us money.

(Boys, FGD)

Exchanges with adults are not simply time-limited financial transactions, but may involve long-term relationships that the youth can draw in times of trouble or need.

Sex between male peers occurred for different reasons, including lack of female partners, to relieve desire or seek 
comfort, or in exchange for material objects. Sex was also described as a way of controlling the group's behavior and punishing rule-breakers in the ronda (circle), a ritualized gang rape:

-For example, we go steal, then the guy goes to sell the stuff, then he's arrested, they (police] take him, hit him, try to find out where the stuff is. When he gets back to the street, the guys want to get even. - So we put him in the ronda and everyone does it to him.

-We make a circle, put him in the middle, tell him to take off his clothes, and everyone has sex with him.

(Boys, FGD)

Survey respondents were not asked about their own experience of rape, but a fifth of the sexually active youth said their male friends had been forced to have sex against their will.

Girls' sexual partners and practices. Among sexually active girls, sexual experience with opposite sex partners was almost universal but same-sex experience was rare (Table 4). Vaginal intercourse was reported by most girls, and oral and anal intercourse by subsets of the girls. Sex with male peers was described as a source of protection, punishment, and pleasure. On the streets, linking up with a respected partner is one way of defending against sexual harassment:

It $[$ ronda] never happened to me, you know, I came to the street alone, I didn't have anyone but I found a smart guy for myself, a guy who not just anyone would come up to and get in his face. (F., female, 22)

The ronda was described as a way to make girls available sexually to the group as well as to punish transgressors:

The ronda is like this. While one goes in front, another goes in back, another in the mouth. . you know? [All at the same time?] Yes, they cut the girl's hair, they hit her, they do anything they want, you know, and if the girl's a virgin behind, they don't even want to know, they don't have any affection, they're just like rapists. It is a rape, except that in the street it's called ronda, but it's a rape. (F., female, 22)

Girls must find a way to survive on the streets and have difficulty balancing the urgent need for protection with the need for achieving some measure of respect and personal satisfaction. Because of this, for girls sex may not be a source of pleasure, at least not initially:

After I turned 18, then I understood, I knew that it could be good, then, it was much better for me. Nowadays I can say, I know what's right and wrong for me, and nowadays I feel happy when I lie down with my partner in bed. (F., female, 22)

Now, you know, in the right circumstances it [sex] isn't bad at all, is it? Because it's a normal thing. Because all women do it. (K., female, 17)

Like the boys, girls described sex with adult men as occurring in exchange for money or other material goods. In the street surveys, two fifths of the sexually active girls reported that their friends exchanged sex for money, and one fifth reported doing so themselves, as illustrated by comments from life history interviews and focus groups:
[K., were you ever involved in prostitution?] Like that, no, now I'm not going to lie to you, aunt, because I'm a very indiscreet person. I stayed with a guy in Rio, you know, really full of money, full of the ready, you know? But I wasn't interested in him, I was interested in his money. And the man fell in love with me, you know? And I'm not going to lie, I had sex with him, you know? I was selling myself, I was selling myself in exchange for the other things. (K., female, 17 years)

-When we walk by after 10 o'clock, any corner has a guy offering money. I don't know if they are from outside [the neighborhood], but they have cars.

(Girls, FGD)

Same-sex experience was infrequently reported by female street youth.

Gender and age differences. Several significant gender differences emerged in patterns of sexual experience, with more boys reporting sexual activity with a same-sex partner, and anal intercourse with any partner (Table 4). It is possible that girls lied about engaging in anal intercourse; however, it was apparent from the qualitative materials that many girls do not engaged in anal intercourse:

I've never done it that way, in back, I've been asked, he asked, but nobody ever forced me. He asked, but I said, 'No, I don't do that. If you want me it's going to have to be the way that I am.' So then he said, 'No, it's OK, I'm not going to push you.' (K., female, 17)

Not the butt! The girls here aren't that shameless. The girls in my gang aren't shameless like that. Because women who give their butts ... (B., male, 16).

Age differences in sexual experience were found for both boys and girls. Older boys were more likely than younger boys to report sex with adult women and with any same-sex partner (Table 5) but were no more likely to report higher rates of specific types of intercourse. Older girls were somewhat more likely than younger girls to report sex with opposite-sex adults, vaginal intercourse, and sex in exchange for money (Table 6).

\section{Sexually transmitted disease, pregnancy, and abortion}

Street youth are at high risk of sexually transmitted diseases (STDs), premature pregnancy and childbearing, and abortion. Half of the sexually active survey respondents said their friends had STDs, and one fifth had done so themselves (Table 4). Rates of STDs increased with age, particularly for boys (Table 5). Many youth experience recurrent bouts of sexually transmitted diseases:

I found out then that D. [female, 17 years, pregnant and with a 3 year old daughter] had syphilis, I spoke to her about the complications this would bring to her baby and she said: 'Oh! I've had treatment, ma'am. I've had more than 40 injections, but the problem is that A. [partner] won't get treatment and gives it back to me again. He has to get treated, I already spoke to him but he won't go. He argues with me, says I don't know anything, almost hits me. It's no good.' (Field notes.)

When I started going out with G., who's dead, I had syphilis and I didn't know it. I had a terrible itching in my vagina and didn't know [what it was]. So I started talking with the people from [a religious 
Table 5. Sexual partners and practices reported by boys of different ages

\begin{tabular}{|c|c|c|c|c|}
\hline & \multicolumn{3}{|c|}{ Age group } & \multirow[b]{2}{*}{$\begin{array}{c}\text { Total } \\
(N=193)\end{array}$} \\
\hline & $\begin{array}{c}9-12 \\
(N=35)\end{array}$ & $\begin{array}{c}13-15 \\
(N=98)\end{array}$ & $\begin{array}{c}16-18 \\
(N=60)\end{array}$ & \\
\hline Opposite-sex partner(s) & 100.0 & 95.9 & 98.3 & 97.4 \\
\hline Peer & 100.0 & 93.9 & 96.7 & 95.8 \\
\hline Adult & 28.1 & 37.8 & 81.7 & $50.0^{* * *}$ \\
\hline Same-sex partner(s) & 21.2 & 33.3 & 40.7 & $33.5^{*}$ \\
\hline Peer & 12.1 & 25.8 & 31.7 & $25.3^{* *}$ \\
\hline Adult & 12.1 & 13.4 & 25.4 & $16.9^{*}$ \\
\hline \multicolumn{5}{|l|}{ Any partner(s) } \\
\hline Vaginal intercourse & 94.3 & 92.9 & 100.0 & 95.3 \\
\hline Anal intercourse & 60.0 & 60.2 & 68.3 & 62.7 \\
\hline Oral intercourse & 42.9 & 28.6 & 51.7 & 38.3 \\
\hline \multicolumn{5}{|l|}{ Risk behaviors } \\
\hline Exchange sex for money & 11.4 & 18.4 & 15.3 & 16.1 \\
\hline Sex while using alcohol/drugs & 25.8 & 37.6 & 60.7 & $43.0^{* * *}$ \\
\hline Previous STD & 8.6 & 11.7 & 43.3 & $21.2^{* * *}$ \\
\hline Ever used condoms & 11.8 & 9.2 & 28.3 & $15.6^{* *}$ \\
\hline Used condoms last intercourse & 5.7 & 5.1 & 16.7 & $8.8^{*}$ \\
\hline Ever got someone pregnant & 6.1 & 11.3 & 51.5 & $23.2^{* * *}$ \\
\hline
\end{tabular}

group] and I couldn't stand it anymore when I peed it was so bad, I couldn't stand it . . . and I died of shame, right-in addition nobody on the street known about this because I never told-and then I told G. and I didn't even want to have sex with him. He took penicillin, I did too. Then after many years, I had a relationship with P., he said he had gonorrhea, but he didn't give it to me. Because I did the tests and they were all negative, even though D.R. says I gave it to him. (K., female, 17)

In addition to STDs, girls are at risk for premature pregnancy, abortion and childbearing. Over half of the sexually active girls in the street survey had been pregnant, and the proportion reporting ever being pregnant increased markedly with age (Table 6). Although abortion is illegal in Brazil, over one quarter of sexually active girls reported one or more abortions (Table 6). When asked about their last abortion, 8 of these 14 girls said it was induced by themselves or another non-medical person, 5 that it was spontaneous, and one that it was medically supervised. In addition, 16 (30\%) of the sexually active female survey respondents had at least one child, and one was currently pregnant.

The high pregnancy and abortion rate suggests that street youth do not utilize contraceptive methods effectively. In the pilot interviews, knowledge about pregnancy and contraception was assessed and found to be low. Although more sexually active youngsters claimed to know how pregnancy occurred and how to prevent it, they were not significantly more likely to give a correct answer than their sexually inexperienced peers (Table 7).

Table 6. Sexual partners and practices reported by girls of different ages

\begin{tabular}{lcccc}
\hline & \multicolumn{4}{c}{ Age group } \\
\cline { 2 - 4 } & $\begin{array}{c}9-12 \\
(N=6)\end{array}$ & $\begin{array}{c}13-15 \\
(N=20)\end{array}$ & $\begin{array}{c}16-18 \\
(N=28)\end{array}$ & $\begin{array}{c}\text { Total } \\
(N=54)\end{array}$ \\
\hline Opposite-sex partner(s) & 100.0 & 95.0 & 100.0 & 98.1 \\
Peer & 100.0 & 70.0 & 57.1 & $66.0^{*}$ \\
Adult & 16.7 & 50.0 & 78.6 & $61.1^{* *}$ \\
Same-sex partner(s) & 16.7 & 5.0 & 14.3 & 11.1 \\
Peer & 16.7 & 5.0 & 3.6 & 5.6 \\
Adult & 0.0 & 0.0 & 10.7 & 5.4 \\
Any partner(s) & & & & \\
Vaginal intercourse & 83.3 & 95.0 & 100.0 & $96.3^{*}$ \\
Anal intercourse & 33.3 & 15.0 & 21.4 & 20.4 \\
Oral intercourse & 50.0 & 35.0 & 32.1 & 35.2 \\
Risk behaviors & & & & \\
Exchange sex for money & 0.0 & 15.0 & 28.6 & $20.4^{*}$ \\
Sex while using alcohol/drugs & 0.0 & 55.6 & 51.9 & 49.0 \\
Ever had an STD & 0.0 & 21.1 & 14.8 & 15.4 \\
Ever used condoms & 0.0 & 20.0 & 39.3 & $27.8^{* *}$ \\
Used condoms last intercourse & 0.0 & 15.0 & 14.3 & 13.0 \\
Ever been pregnant & 0.0 & 35.0 & 75.0 & $51.9 * * *$ \\
Ever had an abortion & 0.0 & 15.0 & 40.7 & $26.4^{* *}$ \\
\hline Data source: street survey; youth with sexual experience only. \\
Data show percentage of respondents reporting each type of experience within each age \\
$\quad$ group. \\
Mantel-Haenszel test for linear association: ${ }^{*} P<0.10 ; * * P<0.05 ; * * * P<0.001$.
\end{tabular}


In the street survey, condom use was assessed and found to be rare and inconsistent. Boys were less likely to report ever having used condoms than girls (Table 4), and of the 45 youngsters who had ever used a condom, only 24 $(53 \%)$ reported using one at last intercourse. The qualitative materials revealed that youth share the cultural disdain for condoms, and carelessness linked to the need for immediate gratification:

-[Why without condoms?]

-Because it feels better.

-There's more attraction.

(Boys, FGD)

-Almost everyone has sex without condoms.

- There are guys who even today say: 'Ah! Condoms are uncool, it has to be without. You don't feel the same thing having sex with a condom ...'

- [But do people use condoms?]

-Yes ... sometimes the girl herself makes the guy use a condom or else she'll have a kid.

-But if the guy doesn't have a condom with him and a girl comes along, they do it anyway.

(Boys, FGD)

\section{Drugs and unsafe sexual practices}

Drugs and alcohol were frequently a part of the sexual experience of street youth. Nearly half of the youngsters interviewed reported having sex while under the influence of alcohol or drugs (Table 4), and this practice increased with age for both boys and girls (Tables 5 and 6). More street- than home-based boys reported having sex while drunk or high $\left(60 \%\right.$ vs $10 \% ; \mathrm{M}-\mathrm{H} \chi^{2}=28.6, d f=3, P$ $=0.00001)$. Boys described using drugs to give them courage to approach potential partners and to dull the pain of having anal intercourse with adult men. Drugs were also used as a means of taking advantage of another person, as in K.'s quote about sexual initiation (above). Youngsters explicitly linked drug use and unsafe sexual practices:

-When some people are on drugs, they have sex any old way. They don't even want to know.

(Boys, FGD)

Table 7. Self-reported and actual knowledge about pregnancy and contraception among sexually experienced and inexperienced youth

$$
\begin{array}{cc}
\text { Experienced } & \text { Inexperienced } \\
\underline{(N=35)} & \underline{(N=28)}
\end{array}
$$

Knowledge about pregnancy

-Percentage who say they know how women get pregnant

-Percentage who gave correct explanation

$\begin{array}{ll}54.5 & 28.6^{*} \\ 38.1 & 33.3 \\ 82.4 & 53.6^{* *} \\ 51.6 & 33.3\end{array}$

Knowledge about contraception

-Percentage who say they know how to prevent pregnancy

-Percentage who gave correct explanation

51.6

33.3

Data source: pilot structured interview.

Differences between sexually experienced and inexperienced youth: $* P<0.10 ; * * P<0.05$.

\section{Gender differences in sexual attitudes}

Attitudes towards sex revealed during focus group discussions and in-depth interviews differed markedly by gender. Whereas boys spoke openly about their sexual activities, described sexual acts in detail, and linked sex with pleasure, girls were more inhibited, were reluctant to go into details about their activities, and linked sex with violence. These gender differences echo those that have been described for the larger society [21].

Boys described sex as involving the discharge of energy in an active manner to derive pleasure, ensure survival, or control the behavior of those around them. When discussing their relationships with girls, women, boys and men, male youth described themselves as active agents who are able to take pleasure from their activities. This open approach to sexuality has a dark side; many boys described forcing partners to have sex, either in the ronda or other settings:

- There was me, M., and C. She was about 16 . We were horny for a girl. She was a little bourgeois, daddy's girl. So I called her and asked the time. When she turned to look at me, the boys ran up and covered her mouth. We took her to a corner of the park, gagged her, and all had sex with her.

(Boys, FGD)

- Sex is bad when you're in the mood and the woman abandons you.

- There are guys who get mad because of that. That's why they hit women.

- If I'm with a woman and when the time comes she says 'no, no, no' I even hit her.

-I don't hit them.

- I swear at them.

-I force her to do it.

(Boys, FGD)

These anecdotes are backed up by the fact that girls were more likely than boys to say their friends had been forced to have sex $\left(42 \%\right.$ vs $\left.16 \% ; \chi^{2}=26.2, d f=1, P<0.0001\right)$.

In contrast to boys, girls described sex as something that is frequently beyond their control and is a potential source of shame even when it is desired. This ambivalence is apparent in F.'s description of her first sexual experience:

I was lying there, I had been going out with the guy a long time, we were stuck at hugs and kisses, hugs and kisses, then one day in the shack where we lived, on the hill, it happened. You know; for me it was a painful thing, Mother of God! And also, just from thinking about going to my house and telling my mother I was already a woman. Ah! I don't know, but at the same time that I was liking it I was not liking it, I didn't feel anything for him. (F., female, 22)

The difficult condition of being a girl on the street is reflected not only in the ways girls referred to themselves, but also in the boys' descriptions of "good girls"- those who stay home, go out only on Saturdays, and don't know anything about sex-and "hussies," who engage in sexual activity, including sexual practices that are regarded as deviant. During a life history interview, K. spoke explicitly about what it means to be a street girl: 
For them, we who don't have family, we are women, street women, because we're in the street. Now, if I were at home, I would be a kid, a girl. Because I don't consider myself a girl, no, I consider myself more of an adult. If I were a virgin I'd say it, but I'm a woman so I say woman.

(K., female, 17)

\section{DISCUSSION}

Youth who are surviving on the streets of a large Brazilian city described a world where sex fulfils multiple needs (e.g. survival, solidarity, pleasure, dominance) and where multiple partners (both adults and peers from inside and outside the social group) and high-risk sexual practices (e.g. anal intercourse, gang rape) are common.

The children and adolescents we studied differ markedly from the general population in their early experience of sexuality. Although it does not make distinctions based on socioeconomic status, research conducted in five Brazilian cities by Pathfinder International [31] revealed that the mean age of first intercourse reported by 15-24 year olds was 15.0 years for boys, and 16.9 for girls, compared to 10.8 and 12.4 years in the present study. The sexualization faced by street youth is common across cultures. Research conducted with North American runaway and homeless youth reveals a similar pattern of early sexual initiation. For example, the mean age of first sexual experience reported by 206 11-18 year olds in runaway shelters in New York was 12.0 years for boys and 12.9 for girls [32]. Similarly, a third of 712 Canadian street youth aged 12 or less were sexually active [15], compared to two fifths of the 912 year olds we interviewed.

Despite the similarities in street youth sexualization worldwide, there are culturally determined differences in how sexuality is structured. The influence of the larger sexual culture is evident in our data; for example, anal intercourse is a common practice in Brazil [20] and condom attitudes are generally negative [22]. Youth in our sample reported higher rates of risky sexual behaviors than have been found in other studies of street youth, including male anal intercourse (63\%, compared to $26 \%$ of American male runaways surveyed by Rotheram-Borus and her colleagues [32]), and low rates of ever having used condoms (18\%, vs $68 \%$ of Canadian street youth [15]).

Many of the sexual encounters youth described were exploitative or coercive. Because street youth carry out their daily lives in public spaces, they are always open to the advances of passers-by and other youth. Street girls appear to be particularly vulnerable to sexual exploitation; by being on the street, girls lose the protection afforded by families and become fair game for males seeking sexual adventure. The results of this are evident in elevated pregnancy rates; Pathfinder [31] found that $12 \%$ of 15-19 year old women from the general population reported ever being pregnant, compared to $64 \%$ of $16-18$ year old street girls interviewed in our study.
The findings reveal that Brazilian street youth engage in sexual behavior that puts them at risk of sexually transmitted diseases, including HIV/AIDS. To explore ways of reducing risk behavior, it is necessary to understand the role of sex in street youths' lives. The qualitative materials reinforce that sex is a multi-determined and entrenched behavior in this population. Sexual activity is a way of ensuring survival, seeking comfort, and finding pleasure. It can also be seen as a way of coping with psychological issues that arise during adolescence. Unlike children and adolescents growing up in more favored circumstances, street youth are not presented with multiple arenas for interacting with the world (e.g. the home, school, sports activities), and do not have the material possessions and surroundings that are necessary in the creation of a self-identity [33]. For them, their bodies are frequently the only thing they possess, and their only way of interacting with the world. Interventions must take into account that sex is one of the few things street children can use in their dealings with the world.

Despite the high-risk profile exhibited by these Brazilian street youth, the incidence of HIV/AIDS is currently lower than has been found among homeless youth and runaways in North America [10, 11, 30]. However, as the epidemic progresses in Brazil, it is likely that the incidence of AIDS among street children and adolescents will increase. If this occurs, it will lead to further stigmatization of street youth, as has already occurred with other populations (e.g. prostitutes, jail inmates, transvestites, intravenous drug users) who are increasingly persecuted and marginalized because they are identified as at risk for HIV infection and have been labelled as threats to the larger society [34]. Street youth are already viewed as an embarrassment or threat to society, and may be imprisoned, abused, or murdered [17, $35]$. At the same time, they occupy a unique position, interacting not only with the low-income neighborhoods where their families live but also with the larger society in whose midst they spend their days. Street youth thus link different segments of the population, serving as .a point of interaction between the higher and lower ends of the social spectrum. The findings presented here suggest that the mode of interaction is frequently sexual, a fact that is implicitly acknowledged by recent reports linking street youth to the spread of HIV among the larger society [36]. To avoid further stigmatization, intervention efforts must avoid identifying street youth as a 'high risk group' and emphasize instead community-wide prevention efforts. Another way of avoiding stigmatizating street youth is to integrate HIV prevention efforts into abroad range of health, education, and other services (G. Barker, personal communication, 24 July 1992).

The present study provides insight into the sexual practices and attitudes of youngsters who live and/or work on the streets of Belo Horizonte, Brazil. As with all studies of sexual behavior, it has a number of limitations. First, its reliance on self-report data means that distortion may have occurred, 
although the use of multiple methods of data collection permitted triangulation and cross-verification of findings. Second, because the data were gathered in one city, caution must be taken in generalizing the findings to other populations of street youth, even within Brazil. Finally, information on sexual partners was gathered from the youngsters and not their partners, so an incomplete picture of motivations and interactions may have resulted. Despite its limitations, this study was successful in obtaining a detailed picture of the sexual world of street youth which informed the development of a culturally and developmentally relevant AIDS prevention program [37]. Similar in depth research is needed to provide information on street youth in other cultures.

Acknowledgements - This project was funded by National Institute for Mental Health grant MH45237. Portions of this paper were presented at the VII International Conference on AIDS, Florence, Italy, 1991.

The authors thank Gary Barker and the reviewers who read drafts of this paper, and gratefully acknowledge the youth agencies who permitted us to work at their sites and the children and adolescents who shared their stories with us.

\section{REFERENCES}

1. UNICEF Annual Report. United Nations, New York, 1989.

2. Barker G. and Knaul F. Exploited Entrepreneurs: Street and Working Children in Developing Countries. Working Paper Number 1, Childhope U.S.A., 1991.

3. Childhope. AIDS: A growing threat to street children. Esperanza 2, October, 1990.

4. Aptekar L. Street Children of Cali. Duke University Press, Durham, NC, 1988.

5. International Center on Adolescent Fertility. Reaching sexually exploited youth. Passages 10(4), 1-2, 1991.

6. Bond L. S., Mazin R. and Jiminez M. V. Street youth and AIDS. AIDS Educ. Prevent. 4, Suppl., 14-23, 1992.

7. Borneman E. Progress in empirical research on children's sexuality. In Handbook of Sexology, Vol. 7: Childhood and Adolescent Sexuality (Edited by Perry M. E.), pp. 201-210. Elsevier, New York, 1990.

8. Brooks-Gunn J. and Furstenberg F. F. Adolescent sexual behavior. Am. Psychol. 44, 249-257, 1989.

9. Lusk M. W. Street children programs in Latin America. J. Sociol. soc. Welfare 16, 55-77, 1989.

10. Rotheram-Borus M. J., Koopman C. and Ehrhardt A. A. Homeless youths and HIV infection. Am. Psychol. 46, 1188-1197, 1991.

11. Luna C. J. and Rotheram-Borus M. J. Street youth and the AIDS pandemic. AIDS Educ. Prevent. 4, Suppl., 1-13, 1992.

12. de Oliveira W. Street kids in Brazil: An exploratory study of medical status, health knowledge and the self. Master's Thesis, the University of Minnesota, 1989.

13. Street Kids International Promoting Independence and Self-respect among Street Children around the World. Street Kids International, Toronto, Canada, 1991.
14. Clatts M. C. Homeless youth and AIDS: Challenges in anthropological practice. AIDS Anthropol. Bull. 3, 8-11, 1991.

15. Radford J. L., King A. J. C. and Warren W. K. Street Youth and AIDS. Federal Centre for AIDS, Ottawa, Canada, 1989.

16. Rotheram-Borus M. J. and Koopman C. Sexual risk behaviors, AIDS knowledge, and beliefs about AIDS among runaways. Am. J. publ. Hlth 81, 208-210, 1991.

17. Connolly M. Surviving the streets. AIDS Action 11, 1-2, 1990.

18. Parker R., Herdt G. and Carbano M. Sexual culture, HIV transmission, and AIDS research. J. Sex Res. 28, 77-98, 1991.

19. Ministerio da Saude. AIDS: Boletim Epidemiologico. Ministerio da Saude, Brasilia, 1992.

20. Parker R. Acquired immunodeficiency syndrome in urban Brazil. Med. Anthropol. Q. 1, 155-175, 1987.

21. Parker. R. Bodies, Pleasures, and Passions: Sexual Culture in Contemporary Brazil. Beacon, Boston, MA, 1990.

22. Parker R. Depois da AIDS: Mudancas no comportamento (homo) sexual. In AIDS: A Terceira Epidemia (Edited by Daniel H. and Parker R.), pp. 102-114. Iglu, Sao Paulo, 1991.

23. Meninos de rua: Os filhos da miseria e do crime. Veja, May 29, 34-44, 1991

24. Orsetti A. S. et al. Urn Tiro de Amor Para Todos Voces. Meninos de Rua: Euducacao em Meio Aberto. Barvane, Belo Horizonte, 1987.

25. Vasconcelos A. SOS Meninas. Companhia Editora de Pernambuco, Recife, Brazil, 1990.

26. Vasconcelos A. Working with street girls. Childhope Conference, Reaching the Hard-to-Reach: Health Strategies for Serving Urban Young Women, Washington, DC, 1991.

27. Luna G. C. Street youth: Adaptation and survival in the AIDS decade. J. Adolesc. Hlth 12, 511-514, 1991.

28. Lebensztajn B. et al. Prevalencia de anticuerpos antiHIV en "ninos de cane" en Sao Paulo, Brazil. Revista Costarricense de Ciencias Medicas 8, 11-13, 1987.

29. Aids atinge garotos de rua. Visao 26 April, 28-29, 1989.

30. Greco D. et al. Seropositivity among children at a juvenile detention center in Belo Horizonte, Brazil. VII Int. Conf. on AIDS, Florence, Italy, 1991.

31. Pathfinder International. Saude reprodutiva do adolescente: Pesquisa em cinco cidades Brasil-1987/1989. Policrom Editorial, Salvador, Brazil, 1991.

32. Rotheram-Borus M. J. et al. Lifetime sexual behaviors among runaway males and females. J. Sex Res. 29, 15-29, 1992.

33. Bettelheim B. A Home for the Heart. Knopf, New York, 1974.

34. Daniel H. and Parker R. A terceira epidemia: O exercicio da solidariedade. In AIDS: A Terceira Epidemia (Edited by Daniel H. and Parker R.), pp. 13-30. Iglu, Sao Paulo, 1991.

35. Dimenstein G. A Guerra dos Meninos: Assassinatos de Menores no Brasil. Editora Brasiliense, Sao Paulo, 1990.

36. O pequeno exercito de portadores. $O$ Globo, 6 October p. 12, 1991.

37. Siqueira E. et al. HIV outreach communication intervention for Brazilian street youth. VIII Int. Conf. on AIDS, Amsterdam, The Netherlands, 1992. 